\title{
THE JULY 27, 1976 TANGSHAN, CHINA EARTHQUAKE-A COMPLEX SEQUENCE OF INTRAPLATE EVENTS
}

\author{
By Rhett Butler, Gordon S. Stewart, and Hiroo Kanamori
}

\begin{abstract}
The Tangshan earthquake $\left(M_{S}=7.7\right)$, of July 27,1976 and its principal aftershock $\left(M_{S}=7.2\right)$, which occurred $15 \mathrm{hr}$ following the main event, resulted in the loss of life of over 650,000 persons in northeast China. This is the second greatest earthquake disaster in recorded history, following the 1556 Shensi Province, Chinese earthquake in which at least 830,000 persons lost their lives. Detailed analyses of the teleseismic surface waves and body waves are made for the Tangshan event. The major conclusions are: (1) The Tangshan earthquake sequence is a complex one, including strike-slip, thrust, and normal-fault events. (2) The main shock, as determined from surface waves, occurred on a near vertical right-lateral strike-slip fault, striking $N 40^{\circ} \mathrm{E}$. (3) A seismic moment of $1.8 \times 10^{27}$ dyne-cm is obtained. From the extent of the aftershock zone and relative location of the main shock epicenter, symmetric (1:1) bilateral faulting with a total length of $140 \mathrm{~km}$ may be inferred. If a fault width of $15 \mathrm{~km}$ is assumed, the average offset is estimated to be 2.7 meters with an average stress drop of about 30 bars. (4) The main shock was initiated by an event with a relatively slow onset and a seismic moment of $4 \times 10^{26}$ dyne-cm. The preferred fault-plane solution, determined from surface-wave analyses, indicates a strike $220^{\circ}$, dip $80^{\circ}$, and rake $-175^{\circ}$. (5) Two thrust events follow the strike-slip event by 11 and $19 \mathrm{sec}$, respectively. They are located south to southwest of the initial event and have a total moment of $8 \times 10^{25}$ dyne-cm. This sequence is followed by several more events. (6) The principal aftershock was a normal-fault double event with the fault planes unconstrained by the $P$-wave first motions. Surface waves provide additional constraints to the mechanism to yield an oblique slip solution with strike $\mathrm{N} 120^{\circ} \mathrm{E}$, dip $45^{\circ} \mathrm{SW}$, and rake $-30^{\circ}$. A total moment of 8 $\times 10^{26}$ dyne-cm is obtained. (7) The triggering of lesser thrust and normal faults by a large strike-slip event in the Tangshan sequence has important consequences in the assessment of earthquake hazard in other complex strike-slip systems like the San Andreas.
\end{abstract}

\section{INTRODUCTION}

The Tangshan earthquake which occurred in northeast China on July 27, 1976origin time $19^{\mathrm{h}} 42^{\mathrm{m}} 54.6^{\mathrm{s}}$ UTC; location $39.6^{\circ} \mathrm{N}, 118.0^{\circ} \mathrm{E}$ (USGS); $M_{S}, 7.7 ; m_{b}, 6.3$ (USGS) - stands in terms of loss of life as the greatest earthquake disaster of modern times. The Times (London) reported on January 6, 1977 an estimate from the People's Republic of China of over 650,000 killed. The city of Tangshan with a population of 1.6 million was virtually destroyed and extensive damage was suffered throughout the densely populated surrounding region. Indeed, Chairman Hua KuoFeng has said that the earthquake caused death and destruction on a scale "rarely seen in history" (The Times, 1977). Without diminishing the significance of this event in human terms, the Tangshan earthquake stands unique as the largest continental intraplate earthquake since the establishment of the World Wide Standardized Station Network (WWSSN). The availability of these data affords us a special opportunity to gain insight into the tectonic processes of this class of earthquake. This varied importance of the Tangshan earthquake sequence merits a detailed seismological study of its faulting mechanism. Some local and regional 
studies of this event have been published in the Chinese literature: Qiu Qun, 1976; Zhu Chuan-zhen et al., 1977; Guo Shunmin et al., 1977; Ding Wenjing, 1978; Chen Pei-shan et $a l ., 1978$. This paper shall be primarily concerned with the following: (1) The analysis of available teleseismic data to obtain source parameters for the main event and principal aftershock. (2) The complexity of the earthquake sequence and its implications for intraplate earthquake processes. (3) Reasons for the enormously high casualties and destruction. In this study, long-period surface waves are analyzed to constrain the overall faulting parameters and seismic moments of the main shock and its principal aftershock. Teleseismic body waves are used to detail the faulting process. Japanese $P$-wave first motions (Katsumata, personal communication, 1976), are incorporated to provide additional regional control.

Seismological data. The location of the main shock and the distribution of aftershocks are plotted in Figure 1. The open and closed circles indicate aftershocks occuring before and after, respectively, the principal aftershock. The main after-

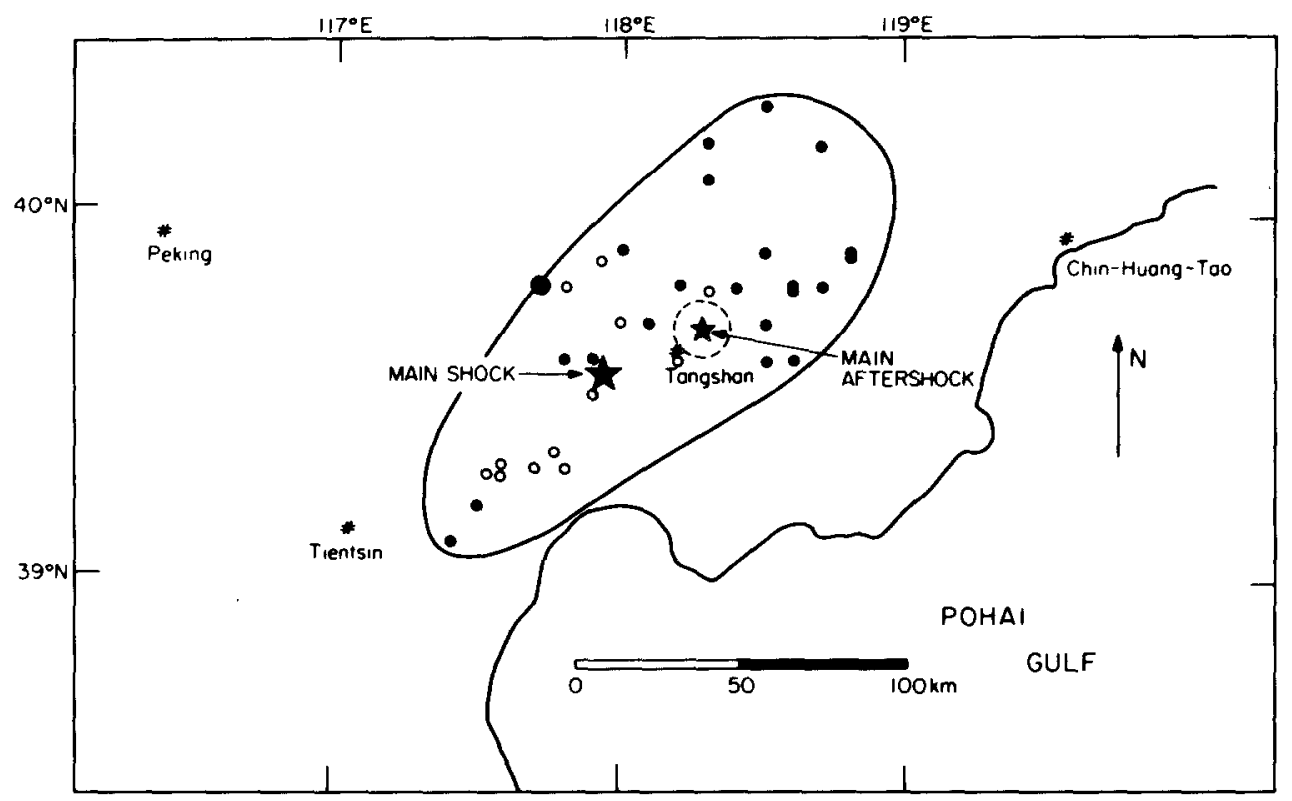

FIG. 1. A map of the main shock, main aftershock, and other aftershock locations (USGS). The open and closed circles are aftershocks which occurred before and after, respectively, the principal aftershock.

shock, an $M_{S}=7.2$ event, occurred $15 \mathrm{hr}$ following the main shock. Locations are taken from the USGS.

$P$-wave first-motion data for the main event are plotted in Figure 2. The dashed line solution is chosen to best constrain the first-motion data. The solid line solution represents the best solution to the surface-wave data. The surface-wave solution is more nearly consistent with the solution obtained by the local Chinese stations (Qiu Qun, 1976). First-motion data for the principal aftershock are plotted in Figure 3. As all stations are dilatational, there is no constraint to the normal fault solution from the $P$-wave first-motion data alone. The solution indicated is constrained by the surface-wave analysis.

Figure 4 shows surface waves G3 (Love waves) and R3 (Rayleigh waves) for the main shock recorded by WWSSN long-period seismographs and equalized to a propagation distance of $360^{\circ}+90^{\circ}$. Surface waves $\mathrm{G} 2$ and $\mathrm{R} 2$ for the principal aftershock, equalized to a propagation distance of $270^{\circ}$, are shown in Figure 5 . The 
equalization procedure is described by Kanamori (1970). As short-period ( $T \leqq 40$ sec) surface waves are severely affected by structural heterogeneities during propagation, these waves are removed by using a filter described in Kanamori and Stewart (1976) with a short-period cutoff at $40 \mathrm{sec}$ and a long-period roll-off at 300 sec. The Love and Rayleigh waves for the main event indicate a four-lobed radiation

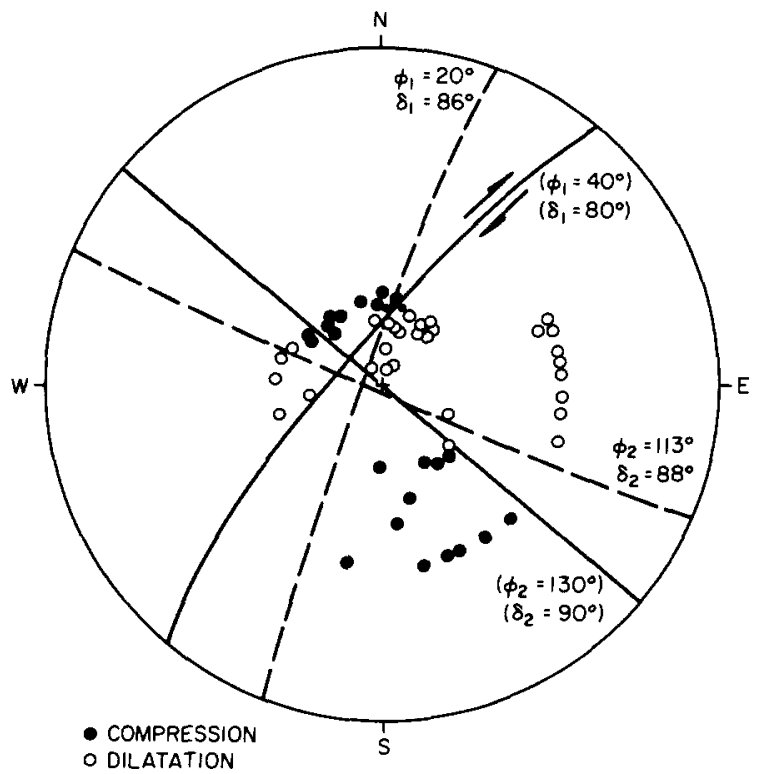

Fig. 2. The $P$-wave first-motion data for the main shock of the Tangshan earthquake sequence. The dashed lines indicate the preferred first-motion solution. The solid lines represent the best solution to the surface-wave data. An equal area projection of the lower focal hemisphere is shown. The arrows indicate right-lateral strike-slip motion of the preferred fault plane of $\mathrm{N} 40^{\circ} \mathrm{E}$.

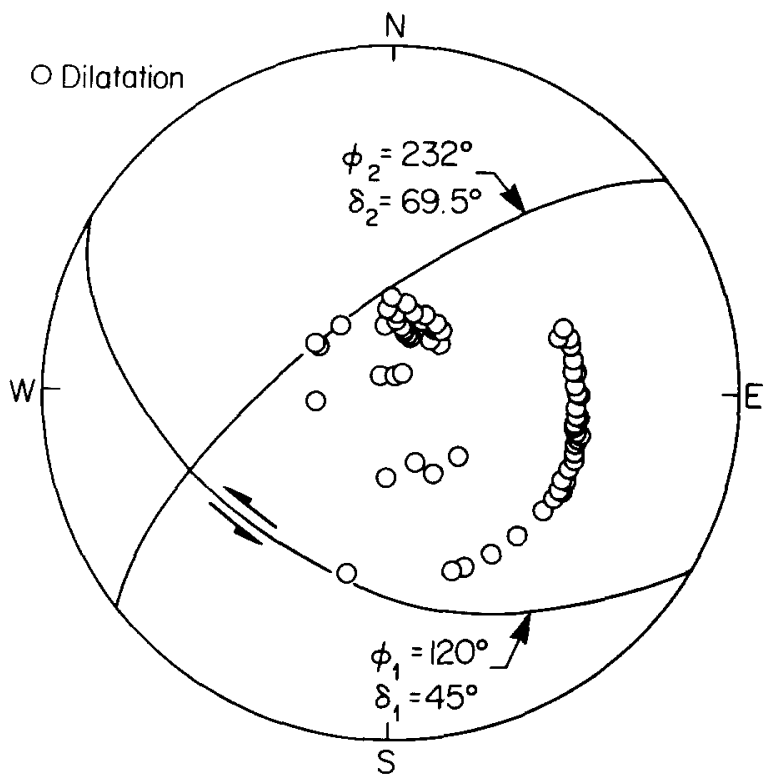

FIG. 3. The $P$-wave first-motion data for the principal aftershock of the Tangshan sequence. All stations registered a dilatational arrival. The solution shown, constrained by the surface-wave data, indicates oblique normal faulting. 
pattern which is consistent with a shallow strike-slip mechanism. However, from the nodal directions, a faulting orientation with a strike of $\mathrm{N} 40^{\circ} \mathrm{E}$ is preferred, slightly rotated with respect to the preferred $P$-wave first-motion solution. This will be discussed in the body-wave analysis section. For the major aftershock the surfacewave radiation is consistent with a dip-slip faulting solution: a four-lobed Love-wave and two-lobed Rayleigh-wave pattern (see Kanamori, 1970). A strike of $\mathrm{N} 120^{\circ} \mathrm{E}$ may be inferred from the nodal directions in the surface waves. The location and strike of this event with respect to a local northwest-southeast trending structural
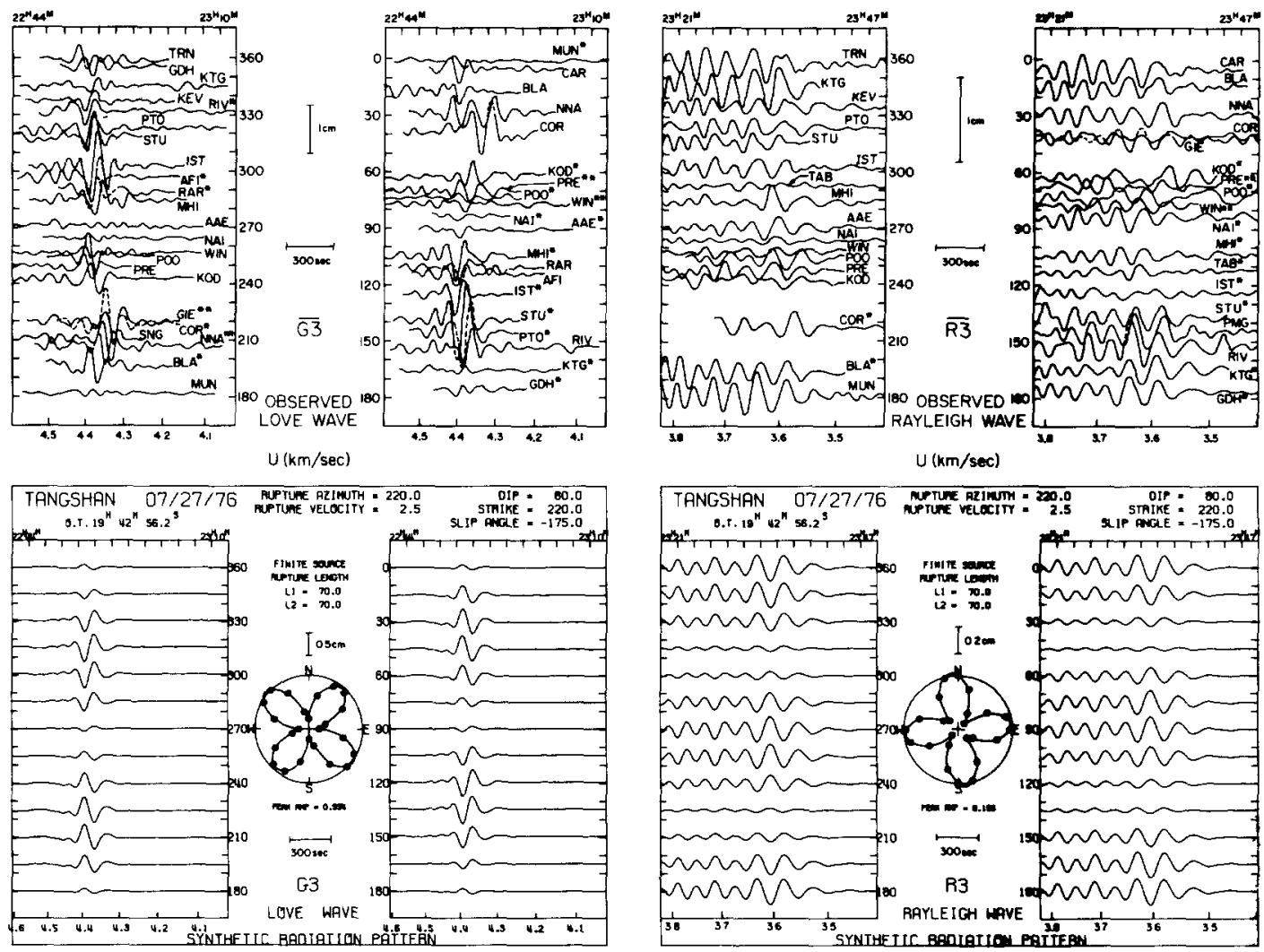

Fig. 4. Azimuthal plots of equalized seismograms for R3 and G3 and synthetic seismograms computed for the main shock of the Tangshan sequence. A source seismic moment of $10^{27}$ dyne-cm is used in the synthesis. In the observed patterns one asterisk indicates that R2 or G2 data were equalized to R3 or G3 distances. Two asterisks indicate that R4 and G4 were equalized to R3 or G3 distances. The amplitude scale is for the trace amplitude on the WWSSN long-period instrument (15-100) with a magnification of 1500 .

boundary observed on the Tectonic Map of China (Geological Science Research Institute of China, 1975) is suggestive of a causal association.

Surface wave analysis. The general pattern of the surface-wave radiation for the main event, as seen in Figure 4 is consistent with the strike-slip solution determined from $P$-wave first motions, with the addition of a small rotation in strike. The geometry of the aftershock zone and the location of the epicenter suggest a northeast trending bilateral fault. Synthetic surface waves were computed for a double-couple at $16 \mathrm{~km}$ depth for a fault geometry with a strike $220^{\circ}$, dip $80^{\circ}$, and slip angle $-175^{\circ}$ (sign conventions are given in Kanamori and Stewart, 1976). The method of synthesis, the velocity, and $Q$ structure are described in Kanamori (1970) and 
Kanamori and Cipar (1974). To be consistent with the aftershock distribution, a small correction for fault finiteness is included assuming a symmetric bilateral rupture $140 \mathrm{~km}$ in length striking $220^{\circ}$ with a rupture velocity of $2.5 \mathrm{~km} / \mathrm{sec}$ (BenMenahem, 1961). The filter used on the observed data is also applied to the synthetics to allow direct comparison. The computed synthetics are shown in Figure

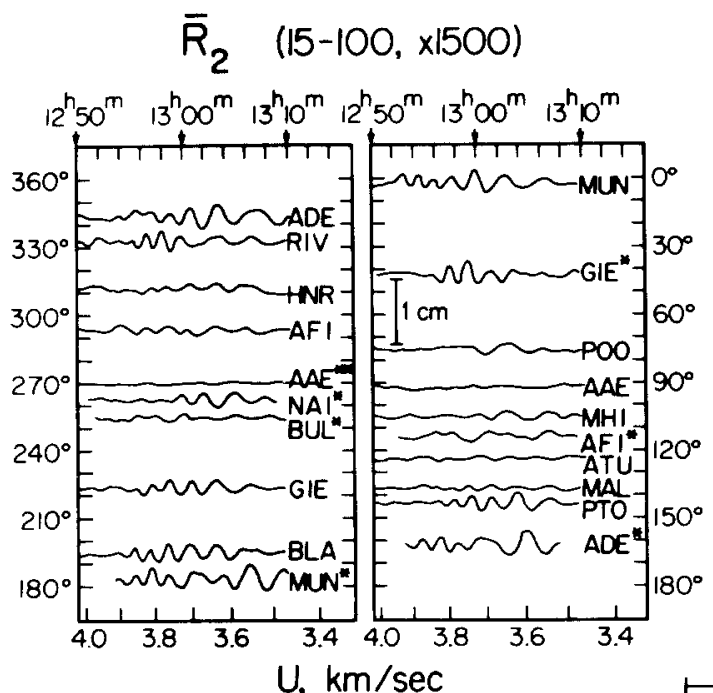

$\bar{R}_{2} \quad\left(M_{0}=10^{27}\right.$ dyne $\left.-\mathrm{cm}\right)$ Synthetic

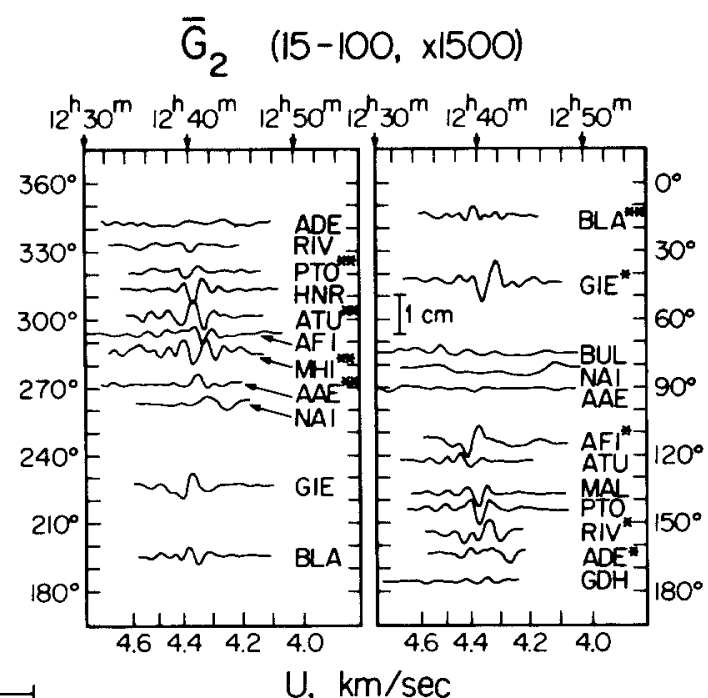

$\mathrm{U}, \mathrm{km} / \mathrm{sec}$

$300 \mathrm{sec}$

$\bar{G}_{2} \quad\left(M_{0}=10^{27}\right.$ dyne-cm) Synthetic
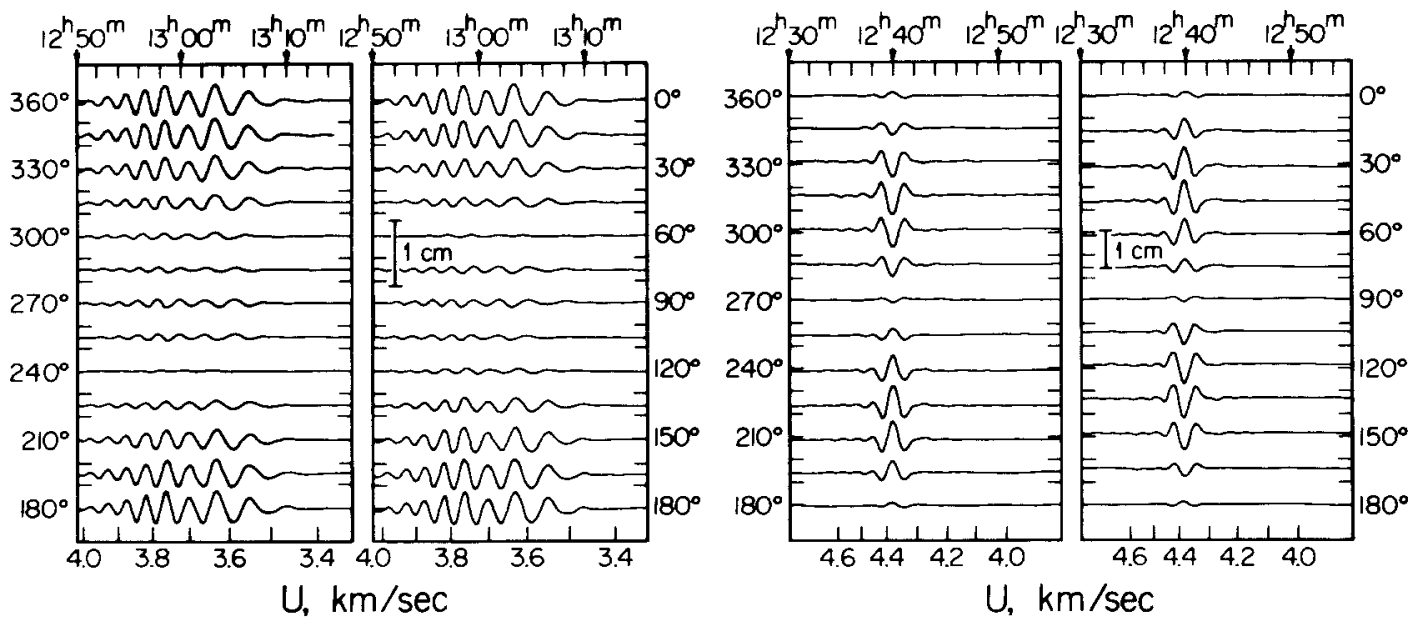

Fig. 5. Azimuthal plots of equalized seismograms for R2 and G2 and synthetic seismograms computed for the principal aftershock of the Tangshan sequence. A source seismic moment of $10^{27}$ dyne-cm is used in the synthesis. In the observed patterns one asterisk indicates that $R 1$ or G1 data were equalized to $R 2$ or G2 distances. Two asterisks indicate that R3 or G3 were equalized to R2 or G2 distances. The amplitude scale is for the trace amplitude on the WWSSN long-period instrument (15-100) with a magnification of 1500 .

4 beneath the observations. In Figure 6 the maximum trace amplitudes of the observed and synthetic records are compared. Using a seismic moment of $1.8 \times 10^{27}$ dyne-cm, a quite satisfactory fit to the observation is obtained.

To model the surface waves for the principal aftershock, we assume a doublecouple at a depth of $16 \mathrm{~km}$, striking $\mathrm{N} 120^{\circ} \mathrm{E}$ with a $45^{\circ}$ dip. The slip angle is varied 
to find the best fit to the observed amplitude ratio between the Rayleigh and Love waves. A slip angle $\gamma=-30^{\circ}$ provides a satisfactory match. Although the effect is minor and probably not observable in the data, source finiteness is included for the sake of completeness to fit the relation of the principal aftershock's epicenter to the overall width of the Tangshan aftershock zone. A bilateral fault (35 by $15 \mathrm{~km}$ ) striking at $120^{\circ}$ with a rupture velocity of $2.5 \mathrm{~km} / \mathrm{sec}$ is assumed. Synthetic Rayleigh and Love waves are shown beneath the observations in Figure 5. The maximum trace amplitude of the observations are compared in Figure 7 to the synthetics. Assuming a seismic moment of $8 \times 10^{26}$ dyne-cm, a reasonably good fit is obtained.

Although details of the extent of faulting have not been released by the Chinese government, rough estimates of the average dislocation $\bar{D}$ and stress drop $\Delta \sigma$ may

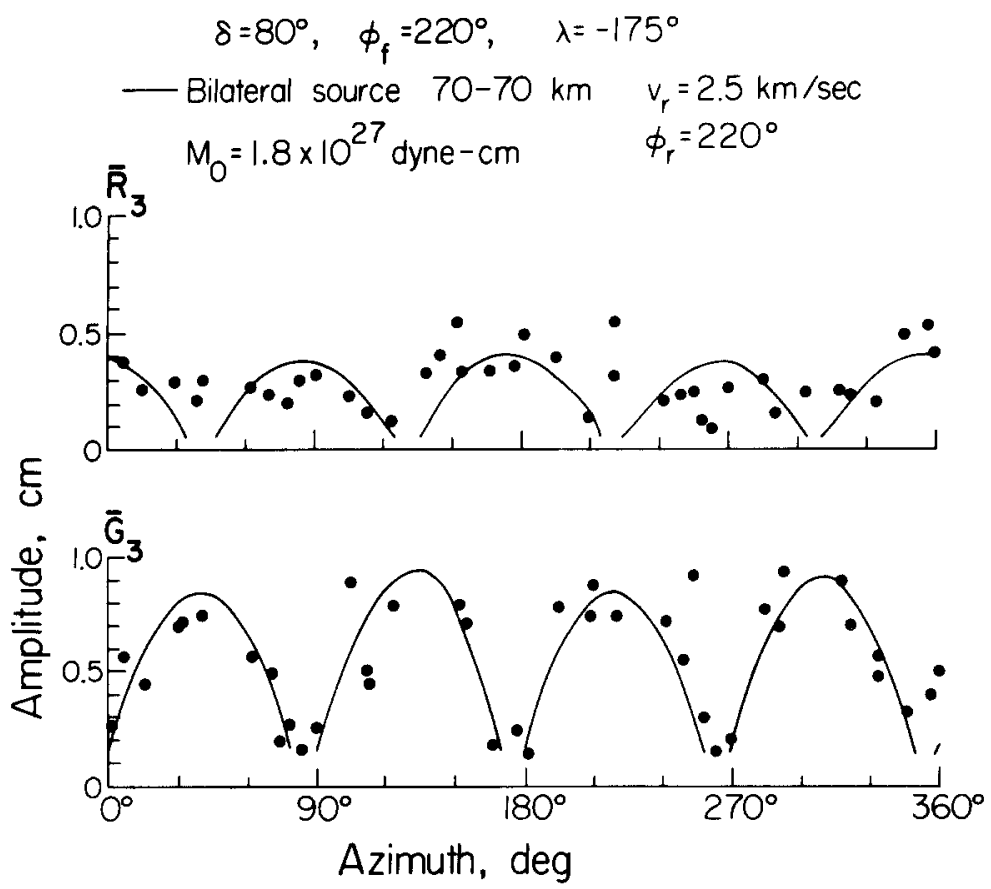

FIG. 6. Equalized station peak-to-peak amplitudes for observed R3 and G3 data from the main event in the Tangshan sequence. The data (solid circles) are plotted as a function of azimuth. The curve represents the fault model used in this study.

be made. A fault length $L=140 \mathrm{~km}$ for the main event can be assumed from the aftershock zone. The vertical extent $w$ is unknown, but for illustrative purposes, $w$ $=15 \mathrm{~km}$ may be assumed. Under these assumptions we have $\bar{D}=M_{0} / \mu L w=2.7$ meters and $\Delta \sigma=2 \mu \bar{D} / \pi w=30$ bars, where a rigidity $\mu=3.5 \times 10^{11} \mathrm{dyne} / \mathrm{cm}^{2}$ is used and the fault is assumed to have broken at the free surface.

Body-wave analysis. The analyses of long-period surface waves for the main event and the principal aftershock yield gross fault parameters, but provide no resolution of details concerning the nature and complexity of the faulting process. To obtain this information, an analysis is made of the teleseismic body waves for these events. Figure 8 shows $P$-wave observations for the main shock. The wave forms are quite complex, but a qualitative description can be made. At the distance range of most of these stations, the only later phase which might interfere with the $P$-wave train is $P c P$. However, for a vertical strike-slip fault $P c P$ is always nodal, so 
that the observed complexity may be ascribed to the source. The initial motion is emergent in nature and reflects the strike-slip solution of the $P$-wave first-motion data. The difference between the teleseismic and local first-motion solutions is probably not significant, as strike-slip mechanisms can be quite sensitive to local nonplanar structure (see Langston, 1977). A later arrival of much larger amplitude is consistently observed (most dramatically at stations RIV, TAU, and ADE). There are two significant peculiarities associated with this arrival: its amplitude does not change sign in the four-lobed manner of vertical strike-slip radiation, and the relative timing of the phase varies with azimuth. These observations suggest that part of the faulting in the Tangshan sequence was not of a strike-slip nature and occurred away from the main-shock epicenter.

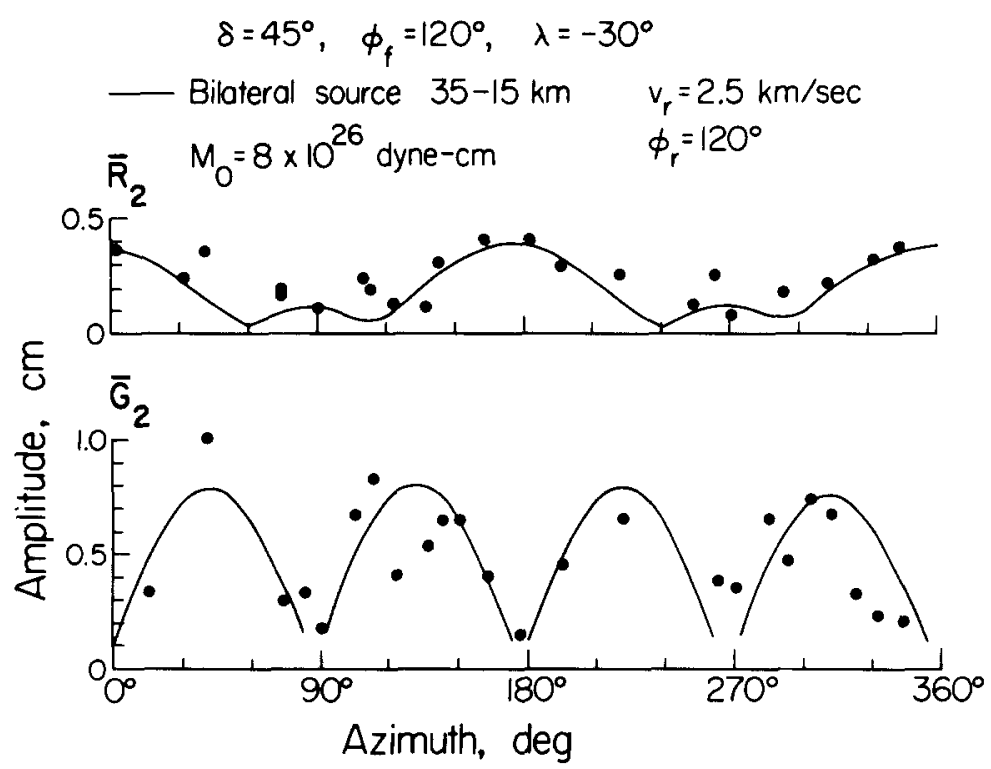

Fig. 7. Equalized station peak-to-peak amplitudes for observed R2 and G2 data for the principal aftershock of the Tangshan sequence. The data (solid circles) are plotted as a function of azimuth. The curve represents the fault model used in this study.

A more quantitative description of the source is obtained by attempting to match the observed records by synthetic wave forms. This technique has been successfully applied to other complex events (Burdick and Mellman, 1976; Kanamori and Stewart, 1978; Rial, 1978). To fit the first portion of the records, synthetics were generated for a point double couple with the mechanism of the $P$-wave first-motion solution at a depth of $10 \mathrm{~km}$ in a homogeneous half-space. The surface reflections $p P$ and $s P$ were included in the synthetics. The faulting solution obtained by first motions provided a qualitatively good match to the observations. However, stations situated near the nodes (see IST) show significant complexities within the first few seconds that are not observed for stations away from the nodes. This is consistent with the hypothesis suggested above of some lateral heterogeneity within the source region. A triangular source time function with a rise time of $5.5 \mathrm{sec}$ and falloff time of $3.25 \mathrm{sec}$ was used to provide an adequate fit to the pulse shape for the non-nodal stations. The seismic moment of this first event is estimated from the average of stations SCH, LON, GSC, RIV, TAU, ADE, and MUN to be $4 \times 10^{26}$ dyne-cm with 25 per cent uncertainty. This solution is fixed and the next arrivals are modeled. 
Kanamori and Stewart (1978) successfully fit $P$-wave seismograms of the 1976 Guatemalan earthquake, a major strike-slip event, by several sources lagged in time and all having identical mechanisms. An attempt to fit the later portion of the $P$ waves of the Tangshan event with a strike-slip solution was fruitless. The azimuthal variation of the relative timing between the first event and the later arrivals can be accounted for by locating the source of these phases roughly $45 \mathrm{~km}$ south to southsouthwest of the epicenter of the main event. By body-wave inversion (see Burdick and Mellman, 1976; Langston, 1976), and trial and error, a satisfactory fit to the observation was achieved by including two thrust events following the initial strikeslip event. The location of these events with respect to the main event is uncertain

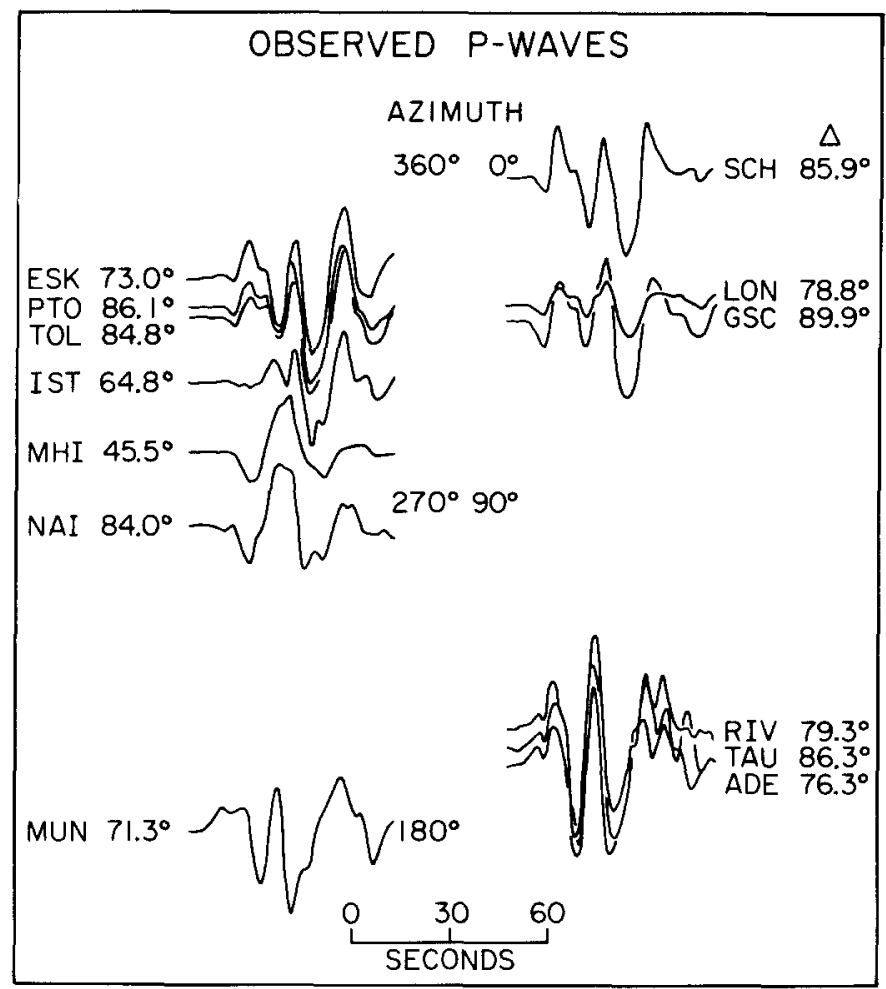

FIG. 8. Observed long-period $P$ waves for the main shock of the Tangshan sequence. The data are plotted as a function of azimuth. The distance in degrees is indicated beside the station name. The amplitudes are corrected for geometric spreading.

to approximately $15 \mathrm{~km}$ distance and $30^{\circ}$ azimuth. The first thrust event occurred roughly 11 sec after the initial strike-slip source and had a relative seismic moment 5 per cent of the initial event. The second thrust source was three times larger and followed the first thrust event by $8 \mathrm{sec}$, or $19 \mathrm{sec}$ from the initial onset of the earthquake. The resolution of the thrust solutions is poor, but a mechanism with a north-northwest strike and a steep dip to the west helped to fit the somewhat different character of the wave forms in the western azimuths. The sum of the moments of these two events, $8 \times 10^{25}$ dyne-cm, is a factor of five smaller than the initial strike-slip solution, but the arrivals from these events dominate the $P$-wave train. This happens because teleseismic $P$ waves for strike-slip events have takeoff angles near the nodes of the radiation pattern, whereas for thrust events the $P$ waves leave near the maximum of the radiation pattern. 
Figure 9 shows synthetics and observations for two representative, non-nodal stations. The fits are satisfactory considering the complications in the problem. Further resolution is not worth pursuing for several reasons. Details of the local crustal structure, particularly the sediment cover, are not documented. The surfacewave analysis has shown that the overall faulting was basically strike-slip, but due to radiation pattern effects small, presumably triggered, thrust events mask the strike-slip radiation. Finally, there is some evidence from first motions and nodal stations that lateral heterogeneity may affect the wave forms. Figure 10 shows shortand long-period vertical component records for Goldstone, California (GSC). The arrival times of the three modeled events are indicated on the short-period record. The emergent nature of the initial strike-slip solution is clearly seen. The longperiod record shows a number of arrivals several minutes after the initial rupture. Presumably a number of these later events are strike-slip, such that the total moment sum of the body waves approaches that of the surface waves, which are

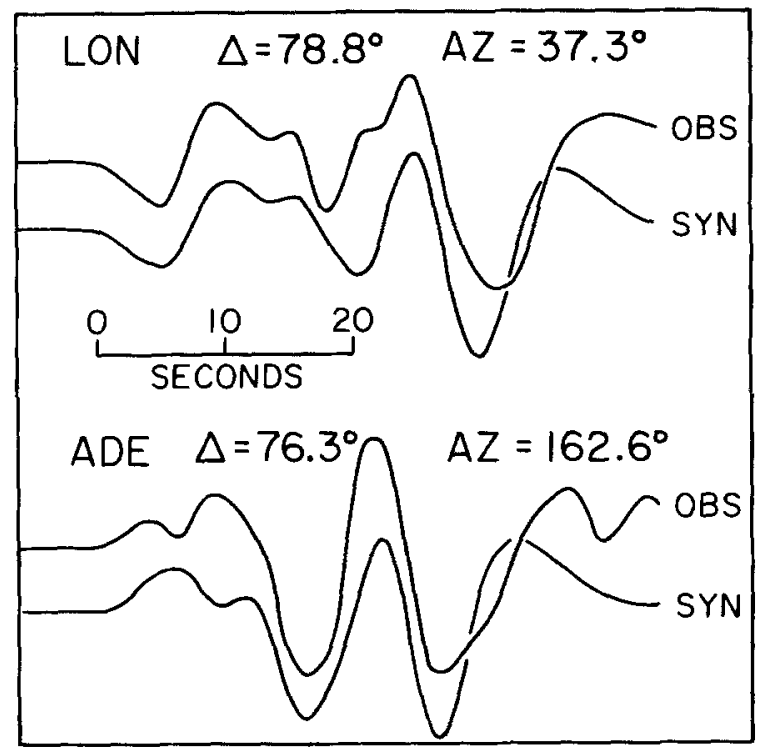

Fig. 9. Observed and synthetic long-period $P$ waves for stations LON and ADE for the main shock of the Tangshan sequence.

sufficiently long period (100 to $200 \mathrm{sec}$ ) to average over the source complexity. Multiple event rupture in strike-slip earthquakes has been observed previously for the 1967 Caracas earthquake (Rial, 1978) and the 1976 Guatemalan earthquake (Kanamori and Stewart, 1978).

Figure 11 shows several $P$ waves for the principal aftershock. The wave forms indicate that the earthquake was a normal faulting double event (see Figure 4 in Langston and Helmberger, 1975). Synthetics were generated for the aftershock to attempt to resolve more information of the faulting. The strike and slip angle are not resolvable, but the amplitude ratio of $p P$ to direct $P$ suggests a dip near $45^{\circ}$ and a depth of approximately $7 \mathrm{~km}$. These constraints assume that the dip of the two mechanisms is similar. There is some azimuthal variation in the amplitude relationship of the two events, but uncertainties in the radiation pattern and in the effect of crustal structure preclude any judgment as to possible differences between the source mechanisms. 

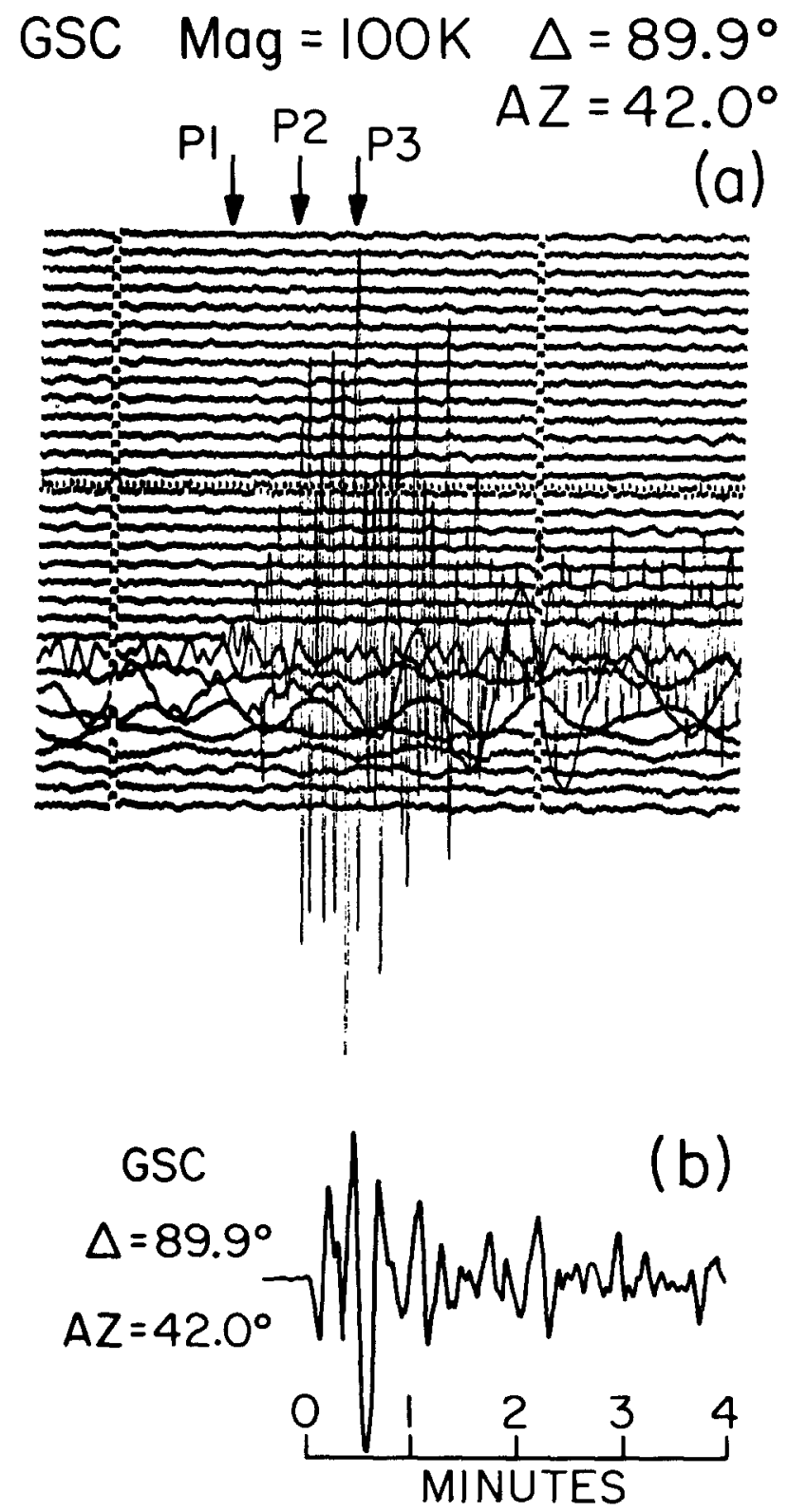

FIG. 10. Observed $P$ waves from the (a) short-period and (b) long-period vertical component seismograms for station GSC at Goldstone, California. The arrows on the short-period record indicate the approximate arrival times of the initial strike-slip shock and the two thrust co-shocks from the main event.

\section{Discussion}

Incorporating the aftershock data and the surface- and body-wave analyses, a faulting scenario of the Tangshan sequence is illustrated in Figure 12. The initial rupture begins rather slowly and has a near vertical strike-slip mechanism, striking $\mathrm{N} 40^{\circ} \mathrm{E}$. The rupture propagates in a bilateral fashion northeast and southwest. After roughly $10 \mathrm{sec}$ the readjustment of the local stress system triggers thrusting 45 $\mathrm{km}$ south of the epicenter. These events, though small with respect to the overall radiation, are roughly of magnitude $M_{w}=6 \frac{1}{2}$ (see Kanamori, 1977). Fifteen hours 
after the main event sequence a large oblique normal event occurs on a northwestsoutheast trending structural boundary. In a simplified view, the system is one of block translation-motion of the southeastern block produces compression at the southern boundary and extension at the northern boundary.

As the Tangshan event is the largest continental intraplate earthquake since the establishment of the WWSSN, it is pedagogically useful to make a comparison with the 1976 Guatemalan earthquake-the largest continental strike-slip interplate event-which was studied in detail by Kanamori and Stewart, 1978. The Tangshan event is smaller both in fault length and moment. Assuming shallow faulting $(w \sim$ $15 \mathrm{~km}$ ) for both events, the average dislocation and stress drop for both events are similar: $\bar{D} \sim 2$ meters and $\Delta \sigma \sim 30$ bars. Both events had associated normal faulting. The normal aftershocks of the Guatemala earthquake were minor in size, whereas

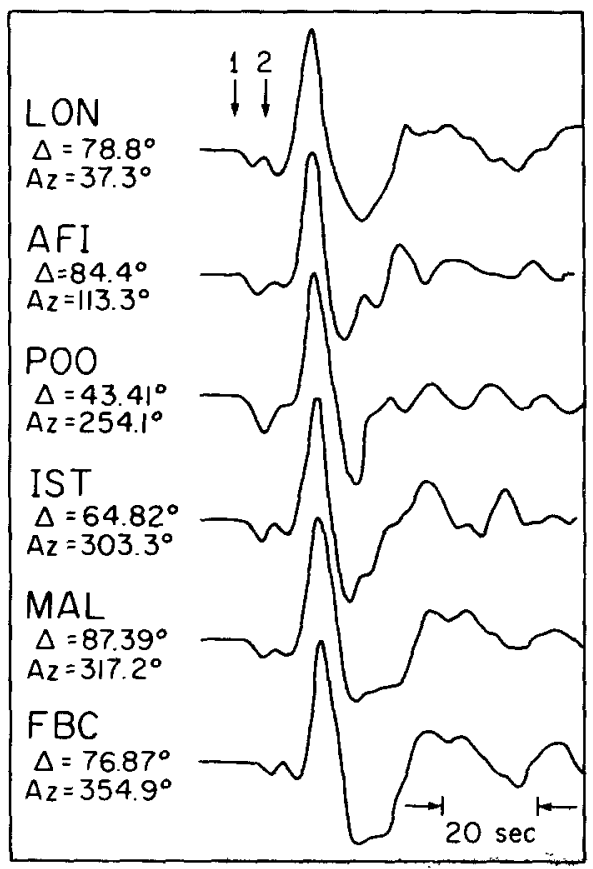

FIG. 11. Observed long-period $P$ waves from the principal aftershock of the Tangshan sequence. The arrows indicate the two shocks of this double event.

the large normal aftershock of the Tangshan earthquake was nearly half the size of the main shock. No thrusting was observed to be associated with the Guatemalan earthquake. Both events consist of a number of smaller independent events. Overall, the Tangshan intraplate earthquake sequence with its variety and size of co-shocks and aftershocks is considerably more complicated in nature than the Guatemalan interplate earthquake.

The enormous loss of life and destruction caused by the Tangshan event importunes an understanding of seismological causative factors. Although the nature of the construction practices in the epicentral region are of primary importance and cannot be discussed within the scope of this paper, three seismological factors are considered to have significantly increased the damage potential. The first relates to the overall nature and complexity of the earthquake. Vertical strike-slip earthquakes radiate most of their energy horizontally into the local source region. Small thrust 
co-shocks enlarged the region of high local intensities. The principal aftershock 15 $\mathrm{hr}$ following the main event was exceptionally large and probably destroyed most structures which were weakened but survived the main shock.

A second seismological factor contributing to the destructiveness of the Tangshan sequence is the effect of the local geology on seismic energy release. The epicentral region of the Tangshan event is an area of sedimentary cover. The thickness of these sediments is not known; however, studies have shown that even moderate thicknesses of sediments effectively amplify seismic intensities relative to nearby bedrock (Gutenburg, 1956, 1957; Borcherdt, 1970). Sedimentary basin structures can also trap and focus the seismic energy (Hong and Helmberger, 1978). The effects of

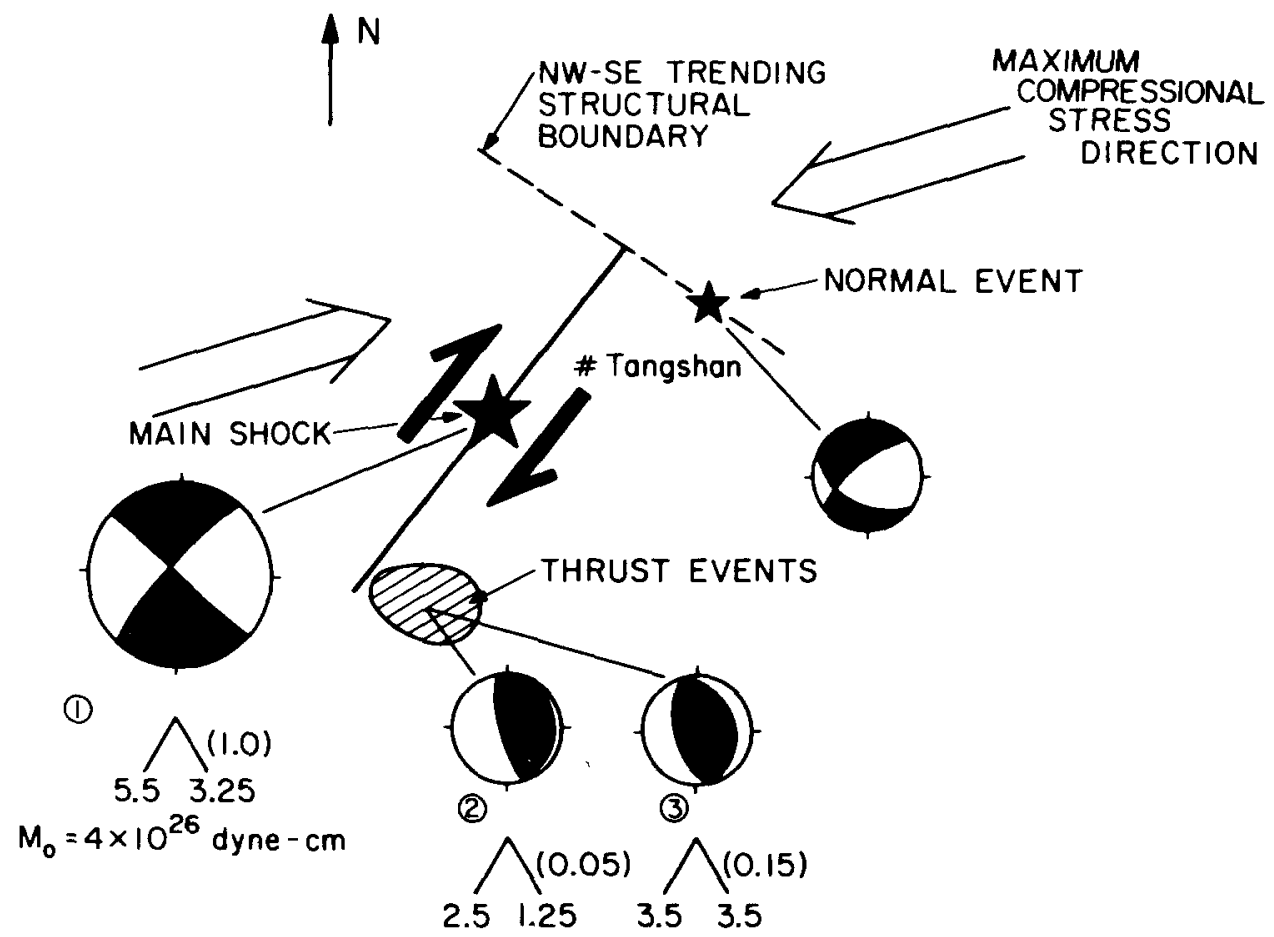

FIG. 12. Seismotectonic illustration of the Tangshan earthquake sequence. Rise times and falloff times for the triangular source-time functions used in the body-wave synthetics of the initial strike-slip shock and thrust co-shocks are indicated. The relative moments are shown in parentheses. No bodywave moment or time function was determined for the normal aftershock.

sedimentary cover, though man-made land fill, were dramatically observed in the 1906 San Francisco earthquake. In the Report of the State Earthquake Investigation Commission on the 1906 event, H. O. Wood (1908) concluded in his discussion of the damage in San Francisco that "... the amount of damage produced by the earthquake ... depended chiefly upon the geological character of the ground. Where the surface was solid rock, the shock produced little damage; whereas upon made land great violence was manifested ..."

A third seismological consideration is with respect to the characteristic falloff of intensity of shaking with distance in the region. This characteristic falloff varies significantly, specifically exemplified in the United States. In the older eastern United States small earthquakes are felt over a much larger area than in the tectonic, younger west. Consequently, earthquakes of a given magnitude tend to be 
more damaging in the east than the west. The reasons for this phenomena are not clearly understood, but are probably related to the attenuative properties of the crust and mantle. It is likely that the intensity falloff characteristics of northeast China are more akin to those of the stable continental eastern United States than the basin and range, tectonic environment of the west. Thus, the region of severe damage for the Tangshan event was probably much larger than would have been true for a similar event on the San Andreas system in California.

\section{Conclusion}

The Tangshan earthquake and its principal aftershock represent a complex intraplate event sequence with strike-slip, normal, and thrust faulting. The main shock was a bilateral strike-slip event, striking north $40^{\circ}$ east. Associated thrusting events occurred south of the main shock epicenter concurrently with the main rupture. The principal aftershock was an oblique normal double event, striking approximately perpendicular to the main shock. The seismic moment of the main event was $1.8 \times 10^{27}$ dyne-cm; the moment for the principal aftershock was $8 \times 10^{26}$ dyne-cm. The complexity of the sequence contrasts the intraplate Tangshan event with the large interplate Guatemala earthquake.

\section{ACKNOWLEDGMENTS}

We would like to thank the personnel of all the WWSSN stations who were kind enough to send us seismograms. This research was supported by a grant from the National Academy of Sciences through WDC-A for seismology, the Division of Earth Sciences, National Science Foundation, NSF grants (EAR76-14262), (EAR77-13641), and (EAR78-11973). Rhett Butler was supported by a Fannie and John Hertz Foundation Fellowship.

\section{REFERENCES}

Ben-Menahem, A. (1961). Radiation of seismic surface waves from finite moving sources, Bull. Seism. Soc. Am. 51, 401-435.

Borcherdt, R. D. (1970). Effects of local geology on ground motion near San Francisco Bay, Bull. Seism. Soc. Am. 60, 29-61.

Burdick, L. J. and G. R. Mellman (1976). Inversion of the body waves from the Borrego Mountain earthquake to the source mechanism, Bull. Seism. Soc. Am.66, 1485- 1499.

Chen Pei-shan et al. (1978). The stress field of the Peking-Tientsin-Tangshan-Zhangjiakon area before and after the Tangshan earthquake of July 28, 1976, Acta Geophys. Sinica 21, 57.

Ding Wenjing (1978). Distribution characteristics and migration regularity of strong aftershock of Tangshan earthquake, Scientia Geol. Sinica No. 1, p. 72.

Geological Science Research Institute of China (1975). Tectonic Map of China, printed by Map Publication Service, China (available from New China Book Store, Peking, China).

Guo Shunmin et al. (1977). Discussion of the regional structural background and the seismogenic model of the Tangshan earthquake, Scientia Geol. Sinica No. 4, p. 321.

Gutenburg, B. (1956). Effects of ground on shaking in earthquakes, Trans. Am. Geophys. Union 37, $757-760$.

Gutenburg, B. (1957). Effects of ground on earthquake motion, Bull. Seism. Soc. Am. 47, 221-250.

Hong, T.-L. and D. V. Helmberger (1978). Glorified optics and wave propagation in nonplanar structure, Bull. Seism. Soc. Am. 68, 1313-1330.

Kanamori, H. (1970). Synthesis of long-period surface waves and its application to earthquake source studies, Kurile Islands earthquake of October, 13, 1963, J. Geophys. Res. 75, 5011-5027.

Kanamori, H. (1977). The energy release in great earthquakes, J. Geophys. Res. 82, 2981-2987.

Kanamori, H. and J. J. Cipar (1974). Focal process of the Great Chilean earthquake May 22, 1960, Phys. Earth Planet Interiors 9, 128-136.

Kanamori, H. and G. S. Stewart (1976). Mode of the strain release along the Gibbs fracture zone. MidAtlantic Ridge, Phys. Earth Planet Interiors 11, 312-332.

Kanamori, H. and G. S. Stewart (1978). Seismological aspects of the Guatemala earthquake of February 4, 1976, J. Geophys. Res. 83, 3427-3434. 
Langston, C. A. (1976). A body wave inversion of the Koyna, India, earthquake of December 10, 1967, and some implications for body wave focal mechanisms, J. Geophys. Res. 81, 2517-2529.

Langston, C. A. (1977). The effect of planar dipping structure on source and receiver for constant ray parameter, Bull. Seism. Soc. Am. 67, 1029-1050.

Langston, C. A. and D. V. Helmberger (1975). A procedure for modelling shallow dislocations. Geophys. J. 42, 117-130.

Qiu Qun (1976). On the background and seismic activity of the $\mathrm{M}=7.8$ Tangshan earthquake, Hopei Province, of July 28, 1976, Acta Geophys. Sinica 19, 269.

Rial, J. A. (1978). The Caracas, Venezuela earthquake of July 1967: A multiple source event, J. Geophys. Res. 83, 5405-5414.

The Times (London), January 6, 1977, p. 1.

Wood, H. O. (1908). Distribution of apparent intensity in San Francisco, in The California Earthquake of April 18, 1906, Report of the State Earthquake Investigation Commission, Carnegie Inst. of Wash., Publ. 87, Washington, D.C. 220-245.

Zhu Chuan-zhen et al. (1977). Source parameters for small earthquakes before and after the $\mathrm{M}=7.8$ Tangshan earthquake, Acta Geophys. Sinica 20, 269.

\section{SEISMOLOGICAL LabORATORY}

California Institute of Technology

Pasadena, California 91125

Contribution No. 3092

Manuscript received June 5, 1978 